\title{
Study on Talents Training Mode of Three Dimensional Digital Design and Manufacturing Based on Combination of 3D and Numerical Control Technology
}

\author{
Jiaofei Huo \\ Xijing University, Xi'an Shaanxi province710123 \\ Shaanxi city of Xi'an province Changan District Xijing Road No. 1 \\ Department of mechanical and electrical technology of Xijing University \\ 710123@qq.com,13571816858@qq.com,95339323@qq.com
}

\begin{abstract}
Keywords: 3D digital design and manufacture; Curriculum system; 3D and numerical control
\end{abstract}
\begin{abstract}
This paper is going to organically combine 3D printing technology and correlated curriculums of numerical control major's training plan to explore the talents training mode of 3D digital design and manufacturing based on the combination of 3D and numerical control technology in the premise of focusing on the 3D digital design and manufacturing and is going to strengthen the comprehensive training sectors.
\end{abstract}

\section{Introduction}

In recent years, the favorable policy environment has caused the stable growth of the numerical control field. However, with the industrial restructuring of economic integration in Shaanxi, traditional manufacturing has upgraded to high-end manufacturing. In addition, traditional numerical control talents are excessive and the major has entered into a bottleneck period. The enrolling number of Numerical Control major and related majors kept decreasing these years and the enrollment situation of higher vocational colleges is in a difficult situation, which directly led to decreasing of Numerical Control major enrollment. Furthermore, the employment rate graduated from numerical control major was also decreasing and most of them are not engaged in related filed after graduation. Therefore, the numerical control major in Shaanxi area is in urgent need of upgrading.

After research, we found out that the labor market is asking for more high-end talents in terms of design and manufacturing filed, and the number is soaring. As a result, there are lots of 3D printing and design talents training centers, which asks colleges to upgrade the traditional numerical control application. Therefore, colleges should timely change the major direction and explore a talent training mode suitable for cultivating high-end talents. Under the support of colleges, we kept studying on issues including: social requirement, industrial development, school-enterprise cooperation, united schools and talents training, aiming to serve the high-end design and manufacturing field. In 2014, we firstly put forth the direction of 3D digital design as well as printing and is going to finally transfer the numerical control major in 2017 . We decide to focus on 3D digital design and printing and hope to obtain abundant achievements. In the meanwhile, we also hope to cultivate comprehensive talents for the high-end design and manufacturing field.

\section{D Printing Technology and Numerical Control Technology have Become Indispensible Technical Means for Modern Manufacturing}

In the government report of Made in China 2025, we can clearly see that it has already highlighted $3 \mathrm{D}$ printing and numerically controlled machine tool, pointed out the development direction of advanced manufacturing technology. Concerning this, experts say that $3 \mathrm{D}$ printing, numerically controlled machine tools, and industrial robot will become the themes that China is going to transfer from manufacturing big nation to a great power.

In the context of $3 \mathrm{D}$ and numerical control technology combination, this paper is going to 
explore the talents training mode of 3D digital design and manufacturing, which will further demonstrate the features of engineering courses. In addition, this paper is also beneficial to deepen and innovate the education system, and realize to cultivate diversified and comprehensive talents.

Modern manufacturing takes advantage of 3D digital design and manufacturing, aiming to realize a concurrent design mode from design to manufacturing process. What's more, it is going to adopt digital 3D data model to possibly reduce (numerical control machining) materials and increase materials (3D printing) in order to optimize the processing procedure, shorten the development cycle time and speed up the listing process.

\section{Problems Remaining to be Solved During the Teaching Process}

Modern manufacturing based on 3D digital design and manufacturing is beginning to focus on 3D $\mathrm{CAD}$ technology as the core to develop digital products, which asks the combination of 3D printing and numerical technology adapts to the talents training target as well as course setting. In addition, we should also make every effort to track advanced manufacturing technology and accurately position the core techniques and professional qualities based on research as well as enterprise-school cooperation to determine the target position of $3 \mathrm{D}$ printing and numerical control technology.

In the premise of carrying out sufficient surveys, this paper is going to focus on 'cultivating comprehensive quality, innovating education based on digital development products to broaden the base and strengthen practical ability.'

\section{Main Contents of 3D Digital Design and Manufacturing}

Construct 3D Digital Design and Printing Course Based on Engineering Projects. Concerning the 15 promising and famous enterprises with a certain scale, we can carry out research, track, analysis, adjustment on the course setting as 3D digital design and printing and introduce new technologies, including Rapid Prototyping, Reverse Prototyping technology and Multiaxis etc.

Construct a Talents Training Platform, Build CAD/CAM Association. Since the establishment of CAD/CAM in 2015, the humane quality of students has been polished a lot based on the association culture construction and students take the associate very seriously. After graduation, students will come back and guide their fellows and juniors students will also assist with the tutoring to improve students' enthusiasm to open a second classroom.

Adopt Social Service Platform, Establish an Elite Team Based on Profession and Education. We should cooperate with high-tech enterprises so as to promote the construction of comprehensive reform experimental area of higher vocational education. Since the opening of reverse engineering projects in May 2015, colleges have established a talents training base, cooperated with enterprises. In the meanwhile, teachers will come visit enterprises to practice, communicate and participate in technological training activities while technological staff of enterprises will come visit schools to carry out professional construction with training, talking about the development trend with teachers. What's more, a teaching project based on entrepreneurship can be conducted so that a team based on profession and education will be established so as to improve the overall quality of the whole faculty team.

\section{Course Setting based on the Combination of 3D and Numerical Technology Combination}

In the premise of combining 3D and numerical technology, technologically applied talents should focus on the reality of modern manufacturing so as to broaden the knowledge and highlight practice. In addition, we should always keep up with the front line of technology and since so that we can timely update and optimize teaching contents. During the process of constructing course setting, we should set the teaching plan, install teaching equipment, train faculties and construct school resources step by step so as to implement the construction of $3 \mathrm{D}$ printing and numerical control course. 
Mechanical Design Manufacturing and Automation Course Setting. The course setting of mechanical design manufacturing and automation should be established based on Foundation of Mechanical Design Technology, Mechanical Manufacturing Technology and Product Design, which should take digital design and manufacturing as features, focus on cultivating students' application ability and strengthen their comprehensive abilities. The whole course setting is made up of theoretical teaching, practice and extra-activities, among which the theoretical teaching can be divided into Public Elementary Courses, Basic Courses, Main Specialized Courses and Major Elective Courses.

Sectors Demonstrating Features of Digital Design and Manufacturing. In course setting, comprehensive and practical sector plays a pivotal role in the whole process and the main contents of practical sectors, digital practice and manufacturing all play very important roles in the whole sector.

In Engineering Graphics Course, and Computer Aided Drawing courses open in the freshmen year, we aim to help students understand the basic training of 3D digital design; in the cognition sector, we also highlight numerically controlled machine tool, 3D printing, sculpturing machine besides $3 \mathrm{D}$ printing and numerical control processing so as to bring about huge changes to the traditional manufacturing.

In sophomore year, we open $3 \mathrm{D}$ software application practice, which can be considered as the core and basic of digital design and manufacturing. Based on high-end 3D CAD/CAE/CAM integrated software UG NX learning, students are expected to understand solid modeling, design, assembling, schedule drawing etc. so as to lay a solid foundation; during computer-aided manufacturing practice, we will ask students to master the principles and methods of NC Automated Programming and be familiar with the CAM mode of UG NXS to complete a complicated program with practice. In practical training of 3D printing, students are asked to master slice software and $3 \mathrm{D}$ printing techniques based on $3 \mathrm{D}$ digital design so that they can participate in course competition with $3 \mathrm{D}$ digital design and manufacturing as the topic.

In senior year, the reverse engineering comprehensive training will be open and it covers a more comprehensive and extensive range from conceptual design, design sketch, volume search and point cloud data processing to design, solid modeling, rapid prototyping. It aims to strengthen students' ability to carry out rapid development based on digital design and manufacturing. During the practical sector of products design and comprehensive training, students should understand the related field of digital management and should be familiar with the operation methods of CAXA V 5 PDM. During the whole process, we will set relative professional training sectors based on the course specialty. For example, in module design and manufacturing, the focus should be $\mathrm{CAD} / \mathrm{CAE} / \mathrm{CAM}$ comprehensive training and students should mainly study module design of Mold Wizard based on UG NXS as well as the application Moldflow module; in graduation design, if the topic is engineering design, then students are expected to complete $3 \mathrm{D}$ design.

\section{Strengthen the Construction of Training Base}

The hardware facilities of Training base is necessary material security to cultivate students practical ability, in order to meet the requirements of modern teaching, in the situation of shortage of funds and avoiding the re-purchase of new equipment, we can combine $\mathrm{CNC}$ machine tools with 3D printer manufacturers, to upgrade the original training equipment, to achieve digital workshop. Using Internet technology, through the network, mobile phones and other terminal equipment, real-timely monitor operation status of equipment in training base, using cloud services provided by $\mathrm{CNC}$ machine tools (CNC system) and 3D printer manufacturers to carry out remote monitoring and online diagnostic functions, seamless docking with the "China Manufacturing 2025 " and " Industrial $4.0 "$.

Improve the Scientific Evaluation Mechanism. Assessment criteria not only is the scale of testing student learning effect, but also the standard to inspire students to face right direction, where there is the kind of evaluation-oriented, there what kinds of effort direction. Establishing a sound, scientific evaluation mechanism will play a positive role in guiding students. 
The current "take dominant curriculum into account, but neglect hidden curriculum", "emphasize results, lighten process", "emphasize current, lighten development" evaluation methods are difficult to adapt to talent requirements from "China Manufacturing 2025". Therefore, It is urgent to establish the multi-evaluation mechanism with employment-oriented, prominent professional ability, paying attention to professional quality, where society, business, school closely integrate with them participate in them. The multiple evaluation mechanism is embodied in the following aspects:

Evaluation content is diversity. It is necessary to attach importance to the practical ability of students, but also refer to the level of theoretical knowledge of students, as well as the comprehensive professional quality of students.

Evaluation means is diversification. In addition to examination results, but also pay attention to process assessment, project assessment, work assessment, on-site assessment, individual differences (progress) evaluation and so on.

Evaluation of the main object is diversification. From the single evaluation from the original traditional school teachers and class director to the evaluation where the society, schools, teachers, enterprises and students to participate in together, through the identification of vocational skills, CNC skills competition, we can introduce the social evaluation into it, through the internship, introducing into the enterprise evaluation (development Evaluation)

\section{Open School}

The coming of "China manufacturing 2025" will bring the depth integration of information technology and manufacturing technology, Internet, Internet of things, large data, cloud computing and other new technologies are got further application in the intelligent manufacturing, and this application is on the basis of information open, traditional closed school on the self-centered is difficult to meet the requirements of modern society for talents, expanding foreign cooperation and exchanges is necessary way to adapt to the new situation.

To carry out foreign learning and exchange, broaden the horizon of teachers. To strengthen the exchange visits, cooperation and exchange of teachers with brother institutions, to learn their school experience; Plan to send teachers to participate in the short-term study and training by national and industry organizations to improve the academic theory of teachers and the level to accept cutting-edge knowledge, updating vocational education teaching idea.

To undertake and participate in three-dimensional digital design and manufacturing skills contest, to enhance the level of teacher profession. Through the organization, participation, guidance skills contest, teachers can master the industry, business skills and the needs of relevant professional positions and technical requirements, and constantly improve their professional level and practical ability to timely update the teaching content, improve teaching methods and teaching quality.

To invite the enterprise personnel into the classroom, creating a corporate culture atmosphere. Inviting the experts, technical engineers from the enterprises to the school, carry out lectures, and employed as part-time internships teachers, bringing their rich frontier knowledge and practical experience into the classroom, so that students directly accept the influence of corporate culture.

To provide social services, carry out social training, test the results of running schools. Making full use of the school's advantages of technology, teachers, equipment, and social and labor departments to carry out technical advice and social services by actively cooperating with social labor departments, to learn the social requirements, train teachers, access to social feedback information, test school results.

\section{Innovation}

Innovate 3D Digital Design and Printing and Act as the Leading Role. After continuous upgrading, the course setting of 3D digital design and printing has been polished, which will definitely help to improve the service quality, faculty quality and skills of our college.

Construct Industrial Innovative Platform and Help with the Professional Upgrading. 
Industrial innovative platform is an initiative, which can be used for teaching, learning, training, skill service, competition, experience exchange, topic research and talent cultivation and will definitely help to enrich resources and construct project construction. Since now, it has taken the responsibility to hold the 3D digital design and manufacturing competitions for a lot of times.

Establish 3D Digital Design and Manufacturing Association, Construct New Ways for Cultivating Innovative Talents. In 3D digital design and manufacturing association, students will participate in social service, innovative projects and skills competition under the guidance of teachers. Through activities, students can get the access to real engineering cases, which will inevitably improve students' real ability to solve problems. Furthermore, it also helps to lay a solid foundation for students to become innovative and applied talents, which is beneficial for entrepreneurship.

\section{Exploration on the Applied Talents Cultivation In Recent Three Years}

Electrical Technology of Xijing University pays attention to both theoretical teaching as well as practice and the comprehensive ability is obviously improved. What's more, it has obtained more than 130 awards in terms of internet innovation competition, comprehensive and skilled talents competition, 3D digital and innovation competition, among which, 14 national first prizes, 22 national second prizes, 45 national third prizes. It is worth mentioning that students are granted 5 awards concerning patents.

We can conclude that in order to be adapted to the upgrading of high-end industry of Shaanxi, and cultivate high quality as well as applied talents, our college has changed the cultivation mode and determined the numerical control direction, namely, 3D digital design and printing. In the meanwhile, we also have carried out research and practice with achievements for higher vocational colleges to refer to regarding major upgrading.

\section{Acknowledgements}

The educational reform subject XiJing University planning .

Serial number:GZJGGH1604

\section{References}

[1] Wu Shaohua. Numerical control construction in vocational colleges based on industrial upgrading LJl. Zjtxjstu. 2013 , (32):16-20

[2] Wang Lingyun, Huang Honghui. Numerical control reform based on industrial upgrading LJl. New Curriculum Research Journal. 2013, (8): 35-37.

[3] Hou Yunxia. Discuss on the numerical control development based on industrial upgrading LJI. Equipment Manufacturing Technology. 2015, (1):241-242.

[4] Wang Zhonghong, Li Yangfan, Zhang Manyin. Current condition and development of 3D printing in China[J]. Jilin: Economic Review2013.(1):90-93

[5] Wang Xueying. Analysis on the development direction of 3D printing [J]. Beijing: China High Technology Enterprises, 2012.(9):3-5

[6] Shi Guirong, Xing Yuan, Zhang Yongqing. Study on the application condition and research direction of reverse engineering [J]. Xian: Mechanical Science and Technology,2000,7(4): 653655.

[7] Ke Yinglin. Reverse CAD system and technology [J]. Rapid manufacturing technologies, 2000, (1):11-14. 